\title{
Organizational Values as 'Attractors of Chaos': An Emerging Supply Chain Management Change Designed to Overcome Organizational Complexity
}

\author{
Guojun Ji* and Yan Zhou**
}

\begin{abstract}
This paper considers supply chain management organizations with the aid of 'chaotic systems theory' developed originally in physics and mathematics. Since innovations in supply chain management are vital for organizational survival 'complex systems theory' may assist in fine-tuning managerial philosophies that provide stability in supply chain management because it is on the boundary of chaos that the greatest innovational creativity occurs. Neither 'management by rigid objectives' $(M B O)$ nor 'management by instruction' (MBI) will be suitable for the information society of the twenty-first century because chaotic social systems will no longer be effectively managed. However, the capacity for self-organization will be derived essentially from how supply chain management members accept a shared set of values or principles for action- 'management by values' (MBV). Complex systems theory deals with systems that show complex structures in time or space, often hiding simple deterministic rules. This theory holds that once these rules are found, it is possible to make effective predictions and even to control the apparent complexity. The state of chaos that self-organizes is attributable to the appearance of the 'strange attractor' and provides the ideal basis for creativity and innovation in the twenty-first century. In the self-organized state of chaos, social members are not confined to narrow roles and gradually develop their capacity for differentiation and relationships, growing progressively towards their maximum potential contribution to the efficiency of the organization. In this meaning, values act as organizers of 'attractors' of disorder, which, in the theory of chaos, are systems represented by usually regular geometric configurations that predict the long-term behavior of complex systems. In supply chain management organizations (as in all kinds of social systems) the initial principles end up as the final principles in the long term. An attractor is a model representation of the behavioral results of the system. The attractor is not a force of attraction or a goal-oriented presence in the system; it simply depicts where the system is heading based on its rules of motion. In supply chain management organizations that cultivate or shares values of autonomy, responsibility, independence, innovation, creativity, and proactivity, the risk of short-term chaos is mitigated by external complexities that organizations are currently confronting. The strategy is to alter the supply chain management's surroundings so that they can benefit from management by values $(M B V)$.
\end{abstract}

Keywords: Complex Systems Theory, Self-organization, Chaos, Supply Chain Management, Information

\footnotetext{
- Professor, School of Management, Xiamen University, Xiamen, Fujian, 361005, China, E-mail: jiking@xmu.edu.cn

" Professor, School of Economy, Financial Department, Xiamen University, Xiamen, Fujian, 361005, China
} 


\section{INTRODUCTION}

Our world has become the global village due to the information highway and the Internet. High-tech based institutions are taking shape driven by information, which has diffused all corners of the world. Generally, traditional companies are information poor whereas modern supply chain managements are information rich. Supply chain management is seeking to discover how information, production and financial flows can be controlled to optimize the company profits where control may be out of balance, Indeed, a good design for the supply chain organization is more pertinent for company development than defining the nature of supply chain management and its organization (Ji, 2003; Fuller, O'Conner and Rawlinson, 1993; Robert, 1982),

After decades of intensive efforts to ensure successful supply chain management within organizations, we have reached the point where it is no longer simple to make savings. Information has become strategic resources and information technologies have been afforded a key role in company development. Before conceding it is a futile objective, we should examine the paradigms and tools that we have been using to understand supply chain organizations. A conclusion emerging from this examination is that if we persist with extant management theories, no significant advances will be made towards a comprehensive understanding of why particular organization succeed. However, if we change our mind-set and view organizational reality through a new prism we may discover pertinent answers.

The supply chain management organization exists to connect factors and structures in such a way as to optimize and identify the supply chain's costs and profitability. Organizational development must be based on the acquisition of information and anticipation of its consequences, to integrate all links or parts to reach connections necessary for integrated management. The lack of integration stems from uncertainty and information asymmetry. Traditional visions of the supply chain management organizations have always searched for the easiest or simplest way to explain how transport or inventories operate. In this section, we have tried to map the universe by examining and explaining its separate parts. However, partial analysis, as opposed to global ones, will give partial solutions.

The importance of holistic perception is embodied in the folk-tale of four sightless people encountering an elephant for the first time. Each described the animal in terms of the part they happened to touch, and four totally disconnected theories about the nature of the elephant emerged. The same partial, even distorted, view of global reality applies to past supply chain management organizational theories. Unfortunately, reality is not as simple as we think; it has complex rules that cannot always be understood through their individual parts.

'Complexity' is a set of characteristics that one can identify in most natural systems, including supply chain management organizations, their processes, operations and planning. A complex system has many natural rules that influence its behavior and exhibits multiple intricacies for dealing with a turbulent environment. You cannot control these natural rules, but you can at least guide them and lead them towards a defined direction. This formula requires the application of an appropriate 
tool, which we propose is the concept of Management by Values (MOV) (Fine, 1999).

\section{COMPLEXITY}

In this section, the complicated nature of supply chain management organizations is demonstrated using complex systems theory. Initially, the parameters that characterize a complex environment are compared in Table 1 with those of the traditional technique (Dolan and Garcia-Sanchez, 1999). Of the parameters outlined in Table 1, attention is concentrated on the concept of chaos as it applies to all supply chain management organizations. Chaos theory seeks to understand the relationship between chaos and order. In this context it is possible to move in both directions: from order to chaos, and from chaos to achieve order.

Table 1. Comparison between a Traditional and Complex Technique

\begin{tabular}{l|l}
\hline \multicolumn{1}{c|}{ Traditional technique } & \multicolumn{1}{c}{ Complexity technique } \\
\hline \hline $\begin{array}{l}\text { Linear: It is possible to predict any system's future } \\
\text { status or behavior through a simple cause-effect } \\
\text { equation. }\end{array}$ & $\begin{array}{l}\text { Non-linear: There's no proportionality in cause- } \\
\text { effect relations, the future is uncertain, the system } \\
\text { reactions are unpredictable, evolution occurs not } \\
\text { continuously but in spurts. }\end{array}$ \\
\hline $\begin{array}{l}\text { Reductionism: The whole is the sum of its parts. } \\
\text { Fractal: The complex whole is made of n-million } \\
\text { interactions of a single pattern that is repeated in } \\
\text { different scales. }\end{array}$ \\
$\begin{array}{l}\text { Control: Chaos is synonymous with disorder. It } \\
\text { should be avoided by controlling the system as } \\
\text { much as possible. }\end{array}$ & $\begin{array}{l}\text { Chaos: There's a right relation between chaos and } \\
\text { order, thus much that one leads to another in a } \\
\text { dynamic process. You don't try to avoid chaos; } \\
\text { instead, you use it to self-organize your system, } \\
\text { through an "attractor". }\end{array}$ \\
$\begin{array}{l}\text { Uniformity: The system does not change in a } \\
\text { sudden way. If it does, it's because something went } \\
\text { wrong; it had not been well controlled. }\end{array}$ & $\begin{array}{l}\text { Catastrophe: One tiny influence can cause } \\
\text { sudden, explosive changes inside a system. }\end{array}$ \\
\hline $\begin{array}{l}\text { Aristotle's Logic: An element can't belong to a set } \\
\text { of elements and to its complementary set at the } \\
\text { same time. }\end{array}$ & $\begin{array}{l}\text { Fuzzy Logic: The relation between elements and } \\
\text { sets of elements is not only yes or no, but a matter } \\
\text { of more or less. }\end{array}$ \\
$\begin{array}{l}\text { Information units: not integration, delayed, and } \\
\text { the value not as subjective decisions. }\end{array}$ & $\begin{array}{l}\text { Information integration: all timely information } \\
\text { may be used in decisions. }\end{array}$ \\
\hline
\end{tabular}

In proceeding from order to chaos, the system passes from a period of uniformity (order) to oscillation, cycles and to turbulence and chaos, until the system 'selforganizes'. Conversely, the analysis of the reverse path from chaos to order uses an element called 'strange attractors', a phenomenon that absorbs or catches the system's final status of order. The importance of strange attractors is that the apparently unforeseen nature of chaos can, in certain aspects, be determined. This is possible 
because a strange attractor has two behavioral patterns:

(1) deterministic, since the attractor defines the system's limit in mathematical terms;

(2) chaotic because such behavior is unforeseeable (i.e., it is impossible to determine where the system's limit is located at each particular moment).

These apparently antagonistic conclusions are illustrated in the graphic representation in Figure 1, which depicts the final geometric state of a chaotic system.

Figure 1. Graphic Representation of an Attractor.

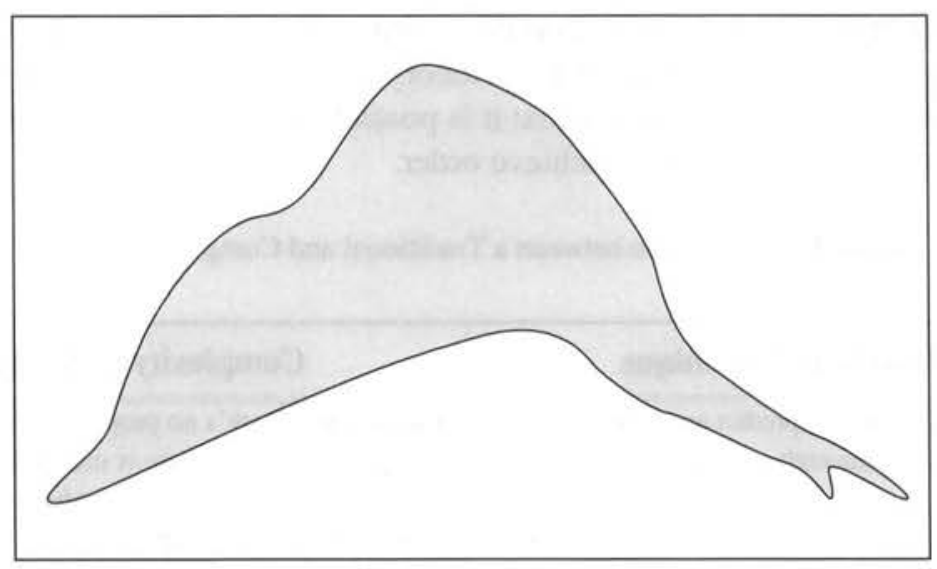

The shaded area represents the limiting possibilities that specify where the system can be at each moment (i.e., the area indicates the deterministic behavior of the strange attractor). Certainly, the system will be found inside this area at any time and nowhere else. Indeed, the area symbolizes the set of values accepted and incorporated by the system. However, it cannot be predicted exactly where, inside the area, the system is located at any specific time; this represents the chaotic aspect of this kind of attractor. The attractor explains a conduct pattern, but not the conduct itself. The presence of a 'strange attractor' guiding the system's behavior is the determining factor that distinguishes between chaos and randomness (Dolan and Garcia-Sanchez, 1999). A random situation is totally unforeseeable, whereas in a chaotic situation the system's set of future behavioral possibilities can be approximately predicted.

\section{CHAOS}

It is important to explain the concept of chaos because it represents 'natural evolution', involving uncertain and chaotic behavior in a turbulent environment. Even in such an apparently complicated situation, nature always organizes itself, as if it were a 'flow'. Actually, this flow exists and it is concerned with a holistic way of thinking about complexity. In order to understand system performance it is more important to analyze the relations between a system and its environment (external relations) rather 
than whole-part relations (internal relations) (Coveney and Highfield, 1995).

If self-organization represents success in reference to a natural phenomenon, we must consider that it is also possible to use the same rules in applying the metaphor of chaos to supply chain management organizations. Nonetheless, we must ask why we need to control uncertainty for so long. A plausible explanation is that the prolongation can reflect the emotional aspects of human beings. One feels secure and stable when situations can be controlled and the future predicted, whereas the unknown brings insecurity and discomfort. The same style of interpretation applies to supply chain management organizations. Supply chain managers not only need comprehensive information drawn from the Internet to help decision-making, but also complain about the disutility of information drawn from traditional sources. Uncertainty triggers insecurity, helplessness and an uncomfortable working environment. In today's information society, control is tantamount to security and power; anyone who is unable to control a work situation is viewed as being powerless and unworthy of respect. These 'explanations' have been supplied by social scientists to account for why people resist change. Paradoxically, most creativity occurs where there is no control at all and only self-governing parameters (i.e., values) can be established.

As noted, turbulent environments are the rule in the business world, not an exception. Supply chain managers using information technology or the Internet overcorrect even if it is harmful for human beings to do so. Therefore, the best strategy of dealing with chaotic behavior is not to try and control it but to develop an understanding of its characteristics. The strategy allows the possibility of following natural flows, even for streams of product, information and cash. We are proposing that chaos cannot be controlled, but it can be guided through behavioral parameters called 'values'. On these grounds the Internet provides 'wealth' not trouble!

\section{TURBULENT ENVIRONMENTS}

As most organizations operate in turbulent environments, the concept of turbulence requires comment. In physics, turbulence involves high-intensity movements seen in fluids, whose flow shows random variations in time and space. This metaphor fits exactly with the turbulent economical, political and informational environments where organizations have to grow and prosper.

In the world of information, supply chain management is now more likely than ever to be global. In this case, turbulence is identified through the existence of unexpected changes, uncertainty, lack of control, inhibition anxiety, complex decisions, group inter-dependency, high performance demand, confusion, disintegration, dehumanization, and neurotic organization (Luhmann, 1990).

The analogy with the complex systems theory suggests that organizations cannot be seen as a separate and distinctive part of this turbulence. The paradigm involves totality. This strategy enables us to deduce that social members are not the product of deterministic rules and regulations, but rather they comprise chaotic dynamics that should be guided by the establishment and incorporation of particular values. The 
challenge for supply chain managers is to know how to guide chaotic dynamics to achieve their desired objectives. To reiterate, chaos self-organizes through the existence of a strange attractor that is responsible for absorbing its final status. 'Final status' does not stand for a static result, but rather a dynamic process of self-organized chaos; it corresponds to the highest point of the supply chain management exchange, where creativity, innovation and development in an organizational system occur.

What remains is to discover how to get to this point of maximum development. We think that one method is through defining the strange attractor set of values. What traditional management approaches fail to achieve is to have confidence in human beings being able to adapt to the turbulent environments in which supply chain organizations operate. Both giving orders (management by instruction), and defining targets (management by objective) do not incorporate dealing with changes in the principal managerial philosophy, and consequently fail to assist supply chain organizations in how to operate in turbulent environments. To deal successfully with complexity, chaos, and turbulence means to be embroiled in constant processes of change, such that the supply chain operation is not only changed by the Internet but also altered by developments within its environment. A common view of managing supply chain organizations implies managing the changes that affects members of the organization directly. For this reason, we should humanize the concepts and tools that are used managing changes within the supply chain process. Maybe, technology is a secondary consideration.

Furthermore, in adapting to changes in turbulent environments, the supply chain manager must be oriented towards the following shared conditions: shared goals and principles that are accepted on behalf of the masses; trust in dealing with uncertainty by decreasing false information; working flexibly within economic conditions and political constraints; developing creativity and innovation in exploring chaotic situations by seeking optimality in supply chain management practices and technological development; simplifying structures and rules given that supply chain management organizations have the capacity to handle complexity and to selforganize; stimulating participation and collaboration; creating social and economical responsibility; engendering high quality relationships between oneself and others; and accomplishing well-being in both ethical and emotional aspects since supply chain management organizations have to work within national and international laws.

Such human adaptation to turbulent environments means dealing with a set of 'new' values incorporated in the daily work inside supply chain management. Values act as 'disorder organizers', and what are defined as principles, in reality result as the long-term ends.

\section{INSTRUCTIONS, OBJECTIVES, AND VALUES}

Traditional management is incapable of absorbing the complexity derived from an increasing need to adapt to change at all levels of supply chain management organizations. Seven inter-connected trends are associated with an increased complexity and uncertainty in supply chain management. 


\section{The Need for Quality and Customer Orientation.}

To compete in an increasingly demanding market, the industrial models or organizations of the $1990 \mathrm{~s}$, orientated toward producing vast quantities of standardized products, are now antiquated and need to be abandoned to ensure that customer is always satisfied with the value received, Competitive conditions require value to be added continuously, customized or personalized in the supply chain company's applications and productive processes. Increasingly, the production focus must be ad hoc, or specific to a particular customer and the prevailing situation. As a result, market segmentation or orientation of the business towards identified customer groups with similar characteristics is reaching the limits of its usefulness. Certainly, it is more complex to orient supply chain management to changing tastes and requirements of demanding customers than to mass-produce standardized items for purchasers with little market power. This first adaptive process is obvious and has been much discussed. The principle suggests that the demand for quality and customer-orientation will be no longer be a competitive advantage, but a basic condition for entry into and survival in the international market place.

\section{The Need to Integrate Multi-knowledge and Multi-technology}

Supply chain management basics incorporate systemic theory, management theory, control theory, signal and code science, language, logic and bibliographic analysis. In the information society the traditional form of global bibliographical control has been substituted. Supply chain management and its uncertainty control are organized using an information system before fresh energy is poured into it. The Internet and information technology development have contributed to the supply chain both new application such as ERP, i2, and Oracle, and new concepts such as eFulfillment, eIntelligence, eProcurement, eMarketplace, ePayment, eRequisitioning, eAuctioning, eBuying, eContracting and eManufacturing.

\section{The Need for Professional Autonomy and Responsibility}

Internet development and the appearance of new technologies such as robotics, process automation and data telecommunication coupled with the reorientation of demand towards quality and the individual client are also increasing. Consequently, there is bound to be an increase in the level of higher professional knowledge and skills that are an integral part of the supply of products and services, and often technology and services. This requires an increase in the general level of professionalism and creativity of employees, which brings with it an increase in the expectations and capabilities of employees to be treated as mature individuals with their own performance criteria. These autonomous, flexible, and committed workers are capable of articulating their own values and translating them into creative initiatives. A professional without autonomy is not a real professional in supply chain management. 


\section{The Need for Transformational Leaders Instead of 'Bosses'.}

This requirement explains why it is increasingly necessary to develop a style of 'facilitating' leadership to ensure that the 'right' events occur. Given its complexity, a supply chain organization demands leadership oriented toward an attractor rather than an ordering instruction or objective. This desideratum also presupposes that orderfollowing workers will be transformed into autonomous professionals. Although many people interpret the concept of leadership in a grandiloquent form, one should not lose sight of its essential characteristics - the capacity to inspire, to articulate a vision, and to hold teams of professionals together and channel their efforts.

\section{The Need for Flatter, More Agile Organizational Structures}

The inefficiency of rigid bureaucratic structures, with many hierarchical levels and watertight compartments, can no longer be tolerated in supply chain management organizations that must compete in turbulent environments. It is widely accepted that a reduction in the number of levels within a hierarchy will be associated with greater organizational flexibility and efficiency. At the beginning of the twenty-first century few would dispute the need for flatter structures, and the development of efficient teams and alliances. Historically, the above-mentioned trends explained the evolution of management philosophies from MBI at the turn of the twentieth century, to MBO at the middle of the century, and thus to management by values (MBV) at the dawn of the twenty-first century. These philosophical shifts are depicted in Figure 2.

Figure 2. Evolution from the $20^{\text {th }}$ to the $21^{\text {s }}$ Century.

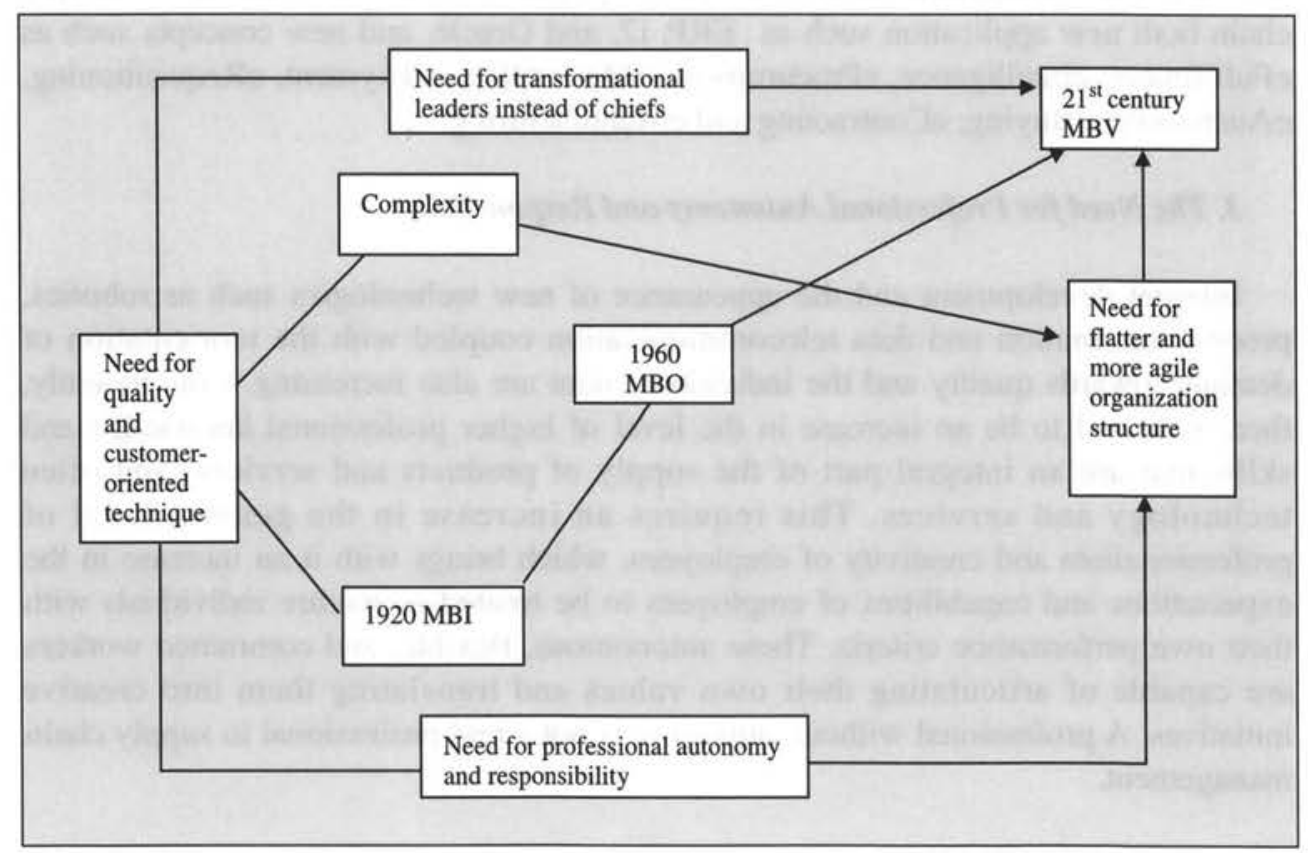




\section{Internal Mechanisms Shown in the Supply Chain's Network.}

First, individual firms are agents that constitute the nodes in the supply chain network. Their actions affect the course of events that occur in the network because they decide how they select clients, choose to move into new markets, and adopt integrated processes of product development involving suppliers and customers. These agents or firms attempt to increase 'fitness' by adhering to a few simple dimensions such as delivery, cost, quality, and flexibility, as reflected in regular supplier performance reports (monthly or quarterly). As reports are filed regularly and subsequent discussions occur common schema are shared between the buyer and suppliers, which leads to a reduction of transaction costs and increased communication efficiency. From this viewpoint, firms that adjust their goals and infrastructural requirements quickly to accommodate changes in their customers, suppliers and competitors will survive longer in the supply chain network. Secondly, only the very simplest supply chain network will have a small number of suppliers (e.g. connected agents) so as to not possess a massively complex, interconnected structure. In fact, a critical level of connectively exists such that there are interconnections among firms that otherwise would assume themselves to be decoupled. Firms that are cognizant of activities across the supply chain (Involving in the tertiary-level suppliers) will be more effective at managing materials flow and technological developments within the network. Thirdly, more autonomy must be provided to the firms in the supply chain's network, essentially to increase dimensionality (i.e. the degrees of freedom available for a potential response). Where suppliers are given autonomy to act creatively, results show that they can develop innovative ideas to improve current product configurations.

\section{Environment Based on Supply Chain Organization Shows Non-linearity}

First, a product, supported by a complicated supply chain network, can be thought of as a system of attributes. These attributes combine in some manner to attach a 'fitness' or 'goodness value' to the product. However, situations, we cannot assume that the overall product or service will improve if all elements in the contributing supply chain's network are upgraded. However, there may be interdependencies that overwhelm locally optimal contributions. For example, a supply chain in which member firms seek to optimize their own local costs may in fact create widely oscillating system behavior called the 'Bullwhip effect' that increases the system's overall costs. From this viewpoint, the modularization of tasks will decrease overall inter-dependencies among firms in a supply chain's network, and offer a higher efficiency when optimizing the overall system. Secondly, there are some coevolutionary factors involving non-linear changes, and non-random futures. Theoretically, it is possible to have a sequential and detached organization of the supply chain's network when radically new products destroy existing supplier-buyer orders throughout the value system. However, the supply chain's network is typically organized in a networked and inter-dependent arrangement where non-linear events occur. From this viewpoint, it is impossible for one firm to control its operations in a 
deterministic fashion. Conversely, the unpredictability of the supply chain's future network corresponds to higher levels of sensitivity. The slightest uncertainty can grow until the system's future becomes impossible to predict when one must be cognizant of impending catastrophic discontinuities. For example, small amounts of perturbation in the consumer market can become amplified and oscillate widely for downstream firms in the supply chain's network. Also, in high-tech industry, we have observed how a small shift in the downstream (consumer market) can become amplified and have a great impact on firms upstream (i.e., equipment manufacturers).

During the early twentieth century, MBI was a necessary complement to the essential characteristics of assembly-line production. In such stable environments, where the objective was to maximize quantity through rationality and discipline, managers instructed and employees obeyed. Even in emergencies, the rules were to be followed without thinking. However, simple and automatic answers in relation to well-defined stimuli do not fit conditions of turbulent environments and unforeseeable situations, especially, in an information society. From the 1960s, the fundamental objective of all organizations was to maximize the profitability of their resources over the long term, and allowed an embryonic supply chain management to start operating within this broad precept. However, this objective was too generic in its aim of rationalizing and motivating the efforts of the people employed. This prescription was distilled into more specific objectives and members of the organization could now formulate their own targets. This was the conceptual foundation of $\mathrm{MBO}$, a management tool that proposed to rationalize and motivate productive efficiency. The tool was based on the principles of 'psychological success', and the theory of goal setting (i.e., it was driven by supply chain management).

Apparently, MBO was more advantageous than MBI. Yet. MBO often falls short of its intended function of rationalizing and motivating value-creating action, precisely because it does not take proper account of the previously discussed premises regarding psychological success and goal-setting theory. $\mathrm{MBO}$ has been proposed as a global system of management while it is, in reality, no more than another tool devised to respond to other much deeper concerns, such as the need to make sense of one's day-to-day work in an organization. Thus MBO has a fundamental defect. Indeed, MBO neglects the human factor, in the sense that objectives only have a meaning when they are intimately linked to people's beliefs and values. Working with values does not mean forgetting objectives. Shared essential values are critical elements on which instrumental objectives are successfully based. As a tool that deals directly with values or attractors of an organization, MBV is oriented toward the redesign of corporate advanced the supply chain products, then, helping leaders guide strategic change in the organizations that will both adapt it to environmental changes and reduce internal tensions (Kets de Vries and Balazs, 1999). MBV's function is to absorb the organizational complexity that comes from its increasing change adaptation necessities and especially to provide a vision through directing the strategic action to where the organization aims to be in the future, its attractor.

This examination of management approaches shows that in turbulent environments, neither instructions nor simple objectives can guarantee organizational 
success. The supply chain management organization is a chaotic social system that can self-organize. Its capacity for self-organization stems directly from the fact that its internal components freely assume a set of shared values or actions conducts. The differences among MBI, MBO, and MBV are listed in Table 2.

Table 2. Different Valuations of Management by Instruction (MBI), Management by Objective (MBO) and Management by Value (MBV)

\begin{tabular}{|c|c|c|c|}
\hline & MBI & MBO & MBV \\
\hline $\begin{array}{l}\text { Preferable situation for } \\
\text { application }\end{array}$ & Routine of emergencies & $\begin{array}{l}\text { Moderate complexity; } \\
\text { relatively "standardized" } \\
\text { production appeared }\end{array}$ & $\begin{array}{l}\text { Need for creativity in the } \\
\text { solution of complex } \\
\text { problems }\end{array}$ \\
\hline $\begin{array}{l}\text { Average level of } \\
\text { professionalism of } \\
\text { members of the } \\
\text { organization }\end{array}$ & $\begin{array}{l}\text { Basic level of instruction } \\
\text { (management of } \\
\text { operatives) }\end{array}$ & $\begin{array}{l}\text { Moderate average } \\
\text { professionalism } \\
\text { (management of } \\
\text { employees) }\end{array}$ & $\begin{array}{l}\text { High level of average } \\
\text { professionalism } \\
\text { (management of } \\
\text { professionals) }\end{array}$ \\
\hline Type of leadership & Traditional & Allocator of resources & $\begin{array}{l}\text { Transformational } \\
\text { (value shape) }\end{array}$ \\
\hline Image of customer & User-buyer & User customer & $\begin{array}{l}\text { Customer with judgment } \\
\text { and demand and } \\
\text { freedom of choice }\end{array}$ \\
\hline Type of product market & $\begin{array}{l}\text { Monopolist, } \\
\text { standardized }\end{array}$ & Segmented & $\begin{array}{l}\text { Highly diversified and } \\
\text { dynamic }\end{array}$ \\
\hline $\begin{array}{l}\text { Type of organizational } \\
\text { structure }\end{array}$ & $\begin{array}{l}\text { Pyramidal with many } \\
\text { levels }\end{array}$ & $\begin{array}{l}\text { Pyramidal with few } \\
\text { levels }\end{array}$ & $\begin{array}{l}\text { Networks, functional } \\
\text { alliances, project } \\
\text { integrated team } \\
\text { structures }\end{array}$ \\
\hline $\begin{array}{l}\text { Need for tolerance of } \\
\text { ambiguity }\end{array}$ & Low & Medium & High \\
\hline $\begin{array}{l}\text { Need for autonomy and } \\
\text { responsibility }\end{array}$ & Low & Medium & High \\
\hline Stability of environment & Stable environment & $\begin{array}{l}\text { Moderately changeable } \\
\text { environment }\end{array}$ & $\begin{array}{l}\text { Very dynamic, } \\
\text { changeable environment }\end{array}$ \\
\hline Social organization & Capitalist-industrial & $\begin{array}{l}\text { Capitalist } \\
\text { post-industrial }\end{array}$ & Post-capitalist \\
\hline Philosophy of control & $\begin{array}{l}\text { "top down" control and } \\
\text { supervision }\end{array}$ & $\begin{array}{l}\text { Control and stimulus of } \\
\text { professional } \\
\text { performance }\end{array}$ & $\begin{array}{l}\text { Encouragement of self- } \\
\text { control by each } \\
\text { individual }\end{array}$ \\
\hline $\begin{array}{l}\text { Purpose of the } \\
\text { organization }\end{array}$ & $\begin{array}{l}\text { Maintenance of } \\
\text { production }\end{array}$ & Optimization of results & $\begin{array}{l}\text { Continuous } \\
\text { improvement and } \\
\text { development of } \\
\text { processes }\end{array}$ \\
\hline Reach of strategic vision & Short term & Medium term & Long term \\
\hline $\begin{array}{l}\text { Basic surroundings } \\
\text { values }\end{array}$ & $\begin{array}{l}\text { Quantitative production, } \\
\text { loyalty, conformity and } \\
\text { discipline }\end{array}$ & $\begin{array}{l}\text { Rationalization, } \\
\text { motivation, efficiency, } \\
\text { measurement of results }\end{array}$ & $\begin{array}{l}\text { Developing } \\
\text { participation, continuous } \\
\text { learning, creativity, } \\
\text { mutual trust, } \\
\text { commitment, enjoy } \\
\text { work }\end{array}$ \\
\hline $\begin{array}{l}\text { Information utilization } \\
\text { degree }\end{array}$ & Isolated, auxiliary & $\begin{array}{l}\text { Partial integrated, } \\
\text { reference }\end{array}$ & $\begin{array}{l}\text { Overall integrated, } \\
\text { shared }\end{array}$ \\
\hline Information feature & Value one by one & Some integrated value & Overall value \\
\hline
\end{tabular}




\section{VALUES}

Basic beliefs and values stemming from creativity in supply chain management creativity are the parameters that lead organizations to future success or failure (Garcia, Dolan and Navaro, 1999). Like attractors, values guide people's behavior and work conduct towards achieving management's desired results. There is a strong analogy between organizational values and strange attractors: both lead a system to its targeted status. The key problem is how to build values into an organization. Values can also be categorized into two main groups: final and instrumental. Final values can be explained as existential objectives, or, the answer to the question: what does your organization seek to achieve in the future? The answer, often embodied in the corporate mission statement, can be economic benefits, excellence in products and services, customer or employee satisfaction, or personal fulfillment and happiness. To achieve these final values, one must define the instrumental ones. Actually, it is necessary to clarify the set of instrumental values that will be used to reach the desired future status.

In Figure 3, instrumental values are organized into two groups: ethical and competence. The ethical values refer to conduct, the means that are justified to achieve the final values. Information issues in the supply chain management organization connect with ethical activity. Usually, these issues are associated with social values such as honesty, integrity, sincerity, and loyalty. Competence values are more individualistic and have to do with the personal impression of what is necessary to achieve final values, or to be competitive. These values include creativity, patience, flexibility, order, intelligence, wide-knowledge, and health. Also Figure 3 shows relations between values, management, and chaos theory. Assuming that final values act as attractors of chaos, they also define the final status of an organization; instrumental values are the system internal values that will lead or organize the chaotic system towards self-government and self-organization.

Figure 3. Values classification and relation to chaos.

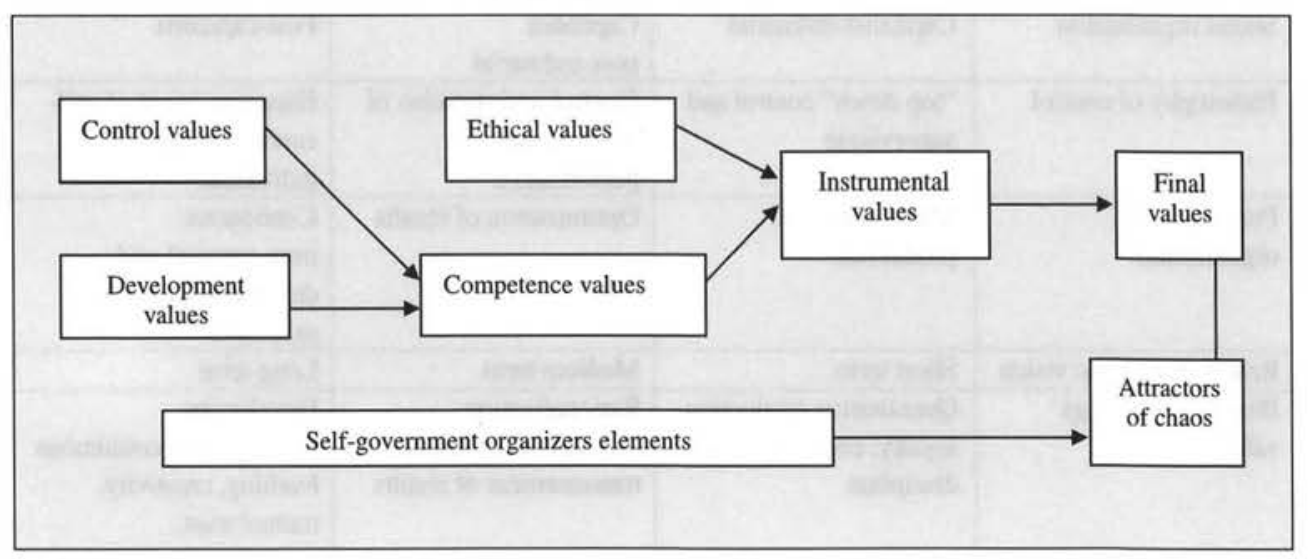


Additionally, there is another important classification of values within supply chain management organizations that keep changing and adapting during their life cycle. These competence values can be either control oriented or development oriented. Depending on their balance, they are responsible for expanding or contracting organizational processes. Examples of control-oriented values are efficiency, discipline, responsibility and punctuality. Trust, freedom, or having fun in the supply chain management activities are examples of development-oriented values.

The above discussion suggests that the inherent chaos within the supply chain management should not be controlled because it stimulates creativity. If left alone, it is able to self-organize through the existence of an attractor. Simultaneously, we should appreciate that supply chain management has many internal quantitative organizational values that could be threatened. Therefore, we need to discover a rule where the two sets of values will co-exist in a balanced manner. As the Internet increasingly provides our world with new content, values oriented toward development are essential to create new opportunities for action. These include selflearning, initiative, diversity, self-organization, and flexibility. Conversely, control values, are also necessary to maintain and bring together the various organizational sub-systems. These values guide such activities as centralization, planning, order, certainty and obedience.

In the natural cycle of growth, any supply chain management organizations need to alternate between moments of development (creating or expanding) and moments of control (consolidating). As in physics, the balance is not maintained by keeping the fluid static in an intermediary state, but rather in its oscillation around a central point. Similarly, supply chain managers should use an adequate mix of values (through control or development) in each situation to achieve an acceptable level of positive results both in economic and social outcomes.

\section{ORGANIZATIONAL CHANGES}

Up to now, we have identified key concepts and elements that should be used in managing change in supply chain management organizations. First, we argued that supply chain organizations are complex systems, thus, they are open and dissipative structures (i.e., they are in a constant adaptive change with their environment, receiving many forms of energy from it and reacting by supplying energy to it). Therefore, supply chain management is a symbol of the modern company's social development. As the twenty-first century business environment is turbulent, supply chain managers cannot be trusted with traditional tools or past approaches. At different levels and depths the current supply chain management situation is continually in a state of dynamic chaos.

The transformational change in supply chain management does not only establish new rules of interaction with the environment but also defines new political and internal interactive rules, such as employee autonomy. These differences are shown in Table 3. 
Table 3. Characteristics of two depth level changes

\begin{tabular}{l|l|l}
\hline & Survival and development conduct & The information change level \\
\hline \hline Adaptive change & $\begin{array}{l}\text { Economic conduct: competitive } \\
\text { interaction for access to environment } \\
\text { resources in relation to competing }\end{array}$ & $\begin{array}{l}\text { Organizational change is derived from } \\
\text { new interactions with market } \\
\text { environment: increasing need to } \\
\text { synchronize technology and structure }\end{array}$ \\
\hline $\begin{array}{l}\text { Transformational } \\
\text { change }\end{array}$ & $\begin{array}{l}\text { Reproductive conduct: transmit the } \\
\text { organization's basic structure to its new } \\
\text { life-cycle generation }\end{array}$ & $\begin{array}{l}\text { The information redefinition of } \\
\text { essential values that construct the } \\
\text { supply chain management } \\
\text { organization's shared identity }\end{array}$ \\
\hline
\end{tabular}

Table 3 shows the main differences between micro and macro changes in relation to complexity within supply chain management. When changes occur smoothly, as in the first case, real adaptation can be labeled as 'shaping' environmental demands to supply chain management; on the other hand, the change is incremental and characterized by peaks and troughs. The macro changes can happen only when new values are established for supply chain management organizations.

The process needs to be considered from a longitudinal or timeline perspective. The supply chain management organization has a structure $\mathrm{X}$ and temporally realizes micro changes are required to better adapt to the situation. This adaptation requires greater complexity within supply chain management until it reaches a critical point, where it becomes necessary to define new values for such system to transform itself and to reappear and/or to be restructured. This change is not smooth but happens suddenly, and can be compared to a catastrophic process where changes are explained as discontinuous transition in structures in order to keep stability. The important contribution in this definition is the fact that a change is the element that keeps an organism's identity, and does it by changing and re-establishing basic values. From the supply chain management organization perspective, this property can be incorporated in a good management model, particularly through the introduction of an advanced information system.

Figure 4 shows the change dynamic inside a supply chain management organization in relation to micro and macro changes. While the supply chain management organization passes through a critical point, new techniques or approaches assist the transformation since new values are incorporated by members of the organization and provoke internal change processes. The same organization is able to 'jump' to a superior level within the new structure. In such a process values act in two ways: (1) as organizers of a shift in supply chain management organization towards the final status; and (2) as the final status itself, or the attractor of this chaotic behavior. At that critical point, values play an important role because, if they fail to reorganize the system, it will fall into different behavioral patterns. If such behavior is non-linear, the results can be different from those expected. 
Figure 4. Organizational change timeline.

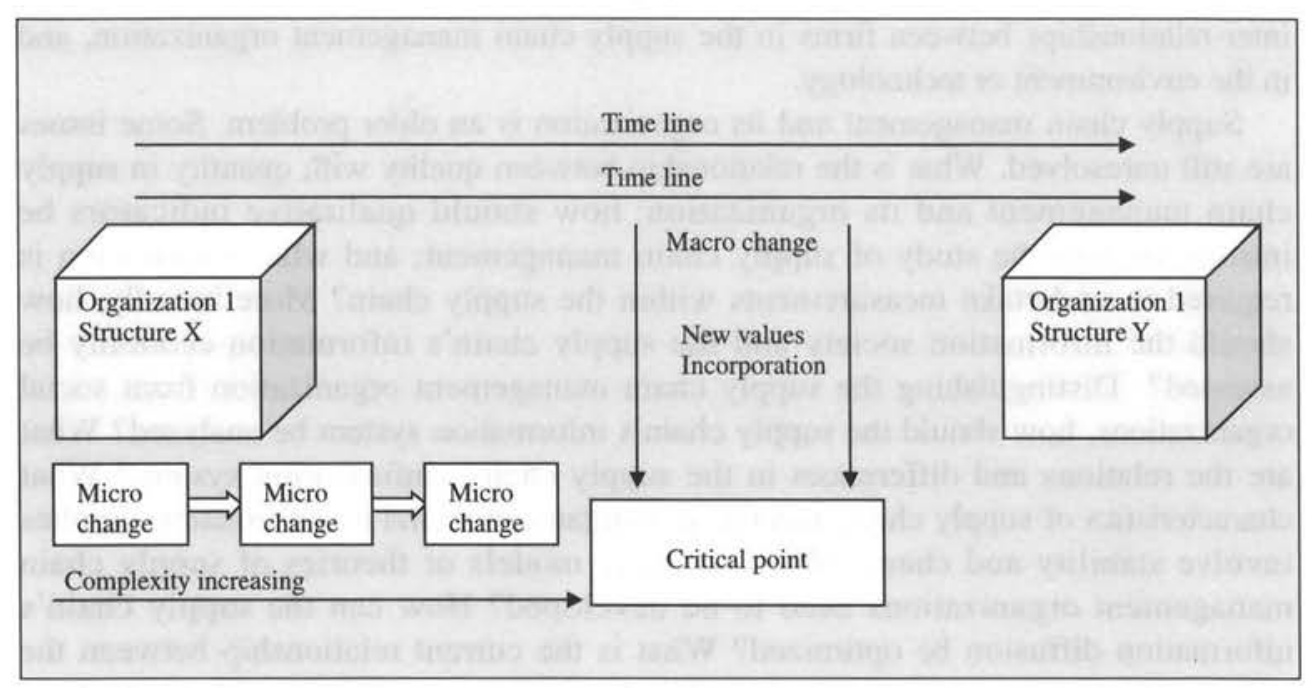

\section{CONCLUSIONS AND UNRESOLVED PROBLEMS}

Qualified leadership of a progressive twenty-first century supply chain management must operate through values. Indeed, the idea of managing change in the turbulent environment of supply chain management refers to the deployment of resources in constructing strategic architecture to bridge the gap between a vision of the future and the organization's present position while confronted by chaos and the need for change.

The turbulence of the international financial system, supply chain managerial environments and the stunning leaps made by technology results in information being distorted as it moves through the supply chain. Further, increasing political instability and technology development are other factors that contribute to chaos and make impractical to plan. For example, Microsoft, that has long dominated its industry, is, at the time of writing, facing dismemberment following allegations by the American government of anti-trust violations. All that an organization can do with some certainty in order to survive is to attempt to construct so-called 'self-fulfilling prophecies' in the arena of organizational values. This strategy will channel activity and decision-making toward a heuristic concept of future success - the principal task of a transformational manager.

For centuries, the benchmarks of a well-run organization have been focused on systems, rules, and procedures to meet immediate objectives. A prime example of this is the oldest form of large-scale task group, the military organization. Increasingly, it is being realized that traditional military roles and rules no long lead to accurate predictions of each outcome. Like other high-tech technology operators, the modern military is gradually coming to grips with the principles of chaos. As complexity 
theory augments traditional systems theory it can be used to assist in recognizing changes within the firm, among supply chain managers, within the market, in the inter-relationships between firms in the supply chain management organization, and in the environment or technology.

Supply chain management and its organization is an older problem. Some issues are still unresolved. What is the relationship between quality with quantity in supply chain management and its organization; how should qualitative indicators be introduced into the study of supply chain management; and what information is required to undertake measurements within the supply chain? More broadly, how should the information society and the supply chain's information economy be assessed? Distinguishing the supply chain management organization from social organizations, how should the supply chain's information system be analyzed? What are the relations and differences in the supply chain's information system? What characteristics of supply chain management organization and its information supplies involve stability and chaos? What dynamic models or theories of supply chain management organizations need to be developed? How can the supply chain's information diffusion be optimized? What is the current relationship between the supply chain's information and commercial structures and Web-based commercial services? How are 'working flows' and 'commercial flows' in supply chain management connected? These unresolved issues should encourage supply chain management organizations to incorporate social developments into their deliberations.

\section{REFERENCES}

Coveney, P. L. and Highfield, R. (1995). Frontiers of Complexity, Fawcett Columbine.

Dolan, S. L. and Garcia-Sanchez, S. (1999). Lagestion par valeurs, Montreal: Editions Nouvelles,.

Fine, Charles H. (1999). Clock Speed, Winning Industry Control in the Age of Temporary Advantage. Reading, Mass., Perseus Books.

Fuller, J.B., O'Conner,, J. and Rawlinson, R. (1993). "Tailored logistics: The next advantage", Harvard Business Review, pp: 87-98.

Garcia S., Dolan, S. L., and Navaro, C.(1999). La direccion por valores para animar la empresa en entorns turbulents, Harvard Business Review, pp: 78-89.

Ji Guojun (2003). "Promote the academic library the information services level in an allround way with the knowledge management innovation, the service innovation and the structural innovation", J. Academic Library, pp: 2-7.

Kets de Vries, M. F. R., and Balazs, K., 1999. "Transforming the mind-set of the organization: a clinical perspective". Administration and Society, 1999, 30(6), pp: 640-675.

Luhmann. N., 1990. Sociadad y sistema: la ambicion de la teoria. Barcelona, Ediciones Paidos,.

Robert, S., 1982. New Science of Management Decision. Beijing, Chinese Social Science Press. 